\title{
The effect of vitreomacular adhesion in exudative age-related macular degeneration on the results of ranibizumab intravitreal injection
}

This article was published in the following Dove Press journal:

Clinical Ophthalmology

II August 2017

Number of times this article has been viewed

\author{
Hiroyuki Suzuki' \\ Seita Morishita' \\ Ryohsuke Kohmoto' \\ Masanori Fukumoto' \\ Takaki Sato' \\ Teruyo Kida' \\ Mari Ueki' \\ Hidehiro Oku' \\ Kimitoshi Nakamura ${ }^{2}$ \\ Tsunehiko Ikeda' \\ 'Department of Ophthalmology, \\ Osaka Medical College, Takatsuki-City, \\ Osaka, Japan; ${ }^{2}$ Nakamura Eye Clinic, \\ Matsumoto-City, Nagano, Japan
}

Correspondence: Tsunehiko Ikeda Department of Ophthalmology, Osaka Medical College, 2-7 Daigaku-machi, Takatsuki-City, Osaka 569-8686, Japan Tel $+8 I 726846434$

Fax +81726820995

Email tikeda@osaka-med.ac.jp
Purpose: To investigate whether vitreomacular adhesion (VMA) affects the outcome of anti-vascular endothelial growth factor (VEGF) therapy for the treatment of exudative agerelated macular degeneration (AMD) in Japanese patients.

Subjects and methods: Of 88 Japanese AMD patients $(28$ men and 60 women, mean age: $72.7 \pm 7.5$ years) who underwent intravitreal injection of ranibizumab for 3 years from 2010 to 2013, this study involved 12 eyes of 12 patients ( 10 men and two women) in whom VMA was observed based on optical coherence tomography (OCT) findings (VMA [+] group) and 17 eyes of 16 patients (seven men and nine women, control group) in whom no VMA was observed (VMA [-] group). In all enrolled patients, ranibizumab was administered monthly for 3 months, and then administered as needed (ie, pro re nata) when deterioration was observed. The two groups were then compared in regard to changes in visual acuity (VA) and the frequency of ranibizumab administration over a 1-year period.

Results: No significant difference was found between the two groups in regard to the transformation of the mean logarithm of the minimum angle of resolution VA change after the first visit. Over the 1-year treatment, the mean frequency of ranibizumab administration for the VMA (+) group was 5.6 \pm 2.5 times and for the VMA (-) group was 3.8 \pm 1.1 times, thus illustrating a significant difference between the two groups (Mann-Whitney's $U$-test: $P<0.05$ ).

Conclusion: Our findings show that the mean frequency of ranibizumab administration for the VMA (+) group was higher than that in the VMA (-) group, thus indicating that VMA might possibly be involved in the progress of AMD pathology.

Keywords: age-related macular degeneration, vitreomacular adhesion, anti-VEGF therapy, ranibizumab, optical coherence tomography

\section{Introduction}

Due to the emergence and increased use of optical coherence tomography (OCT), studies have reported that vitreomacular adhesion (VMA) is involved in the pathologies of some vitreoretinal diseases. Specifically, it has been reported that traction by VMA is an important factor in the cause of idiopathic macular hole, idiopathic epiretinal membrane (ERM), diabetic macular edema, and so on. ${ }^{1-3}$ Recently, there have been reports on whether VMA may possibly be involved in the onset of age-related macular degeneration (AMD). ${ }^{4-20}$ Among those, one study reported that it was difficult to obtain improved visual acuity (VA) with anti-vascular endothelial growth factor (VEGF) therapy in exudative AMD patients with no posterior vitreous detachment (PVD). ${ }^{16}$ However, there have been no reports on race-related differences in AMD and polypoidal choroidal vasculopathy (PCV), or on the relationship between VMA and anti-VEGF therapy in Asian subjects. 
In this present study, we investigated the influence of the presence or absence of VMA on anti-VEGF therapy in Japanese AMD patients who had been treated with intravitreal injection of ranibizumab.

\section{Subjects and methods}

Of 88 Japanese AMD patients (28 men and 60 women; mean age: $72.7 \pm 7.5$ years) who underwent the treatment with intravitreal injection of ranibizumab for 3 years from 2010 to 2013 at the Department of Ophthalmology, Osaka Medical College, Takatsuki-City, Japan, this study involved 12 eyes of 12 patients ( 10 men and two women; mean age: $75.5 \pm 6.7$ years) in whom VMA was observed based on their OCT findings (VMA [+] group), and 17 eyes of 16 cases (seven men and nine women, control group) in whom VMA was not observed and whose ages were matched (VMA [-] group). We diagnosed the choroidal neovascularization $(\mathrm{CNV})$ and the polypoidal region on the basis of fluorescein angiography and indocyanine green angiography in addition to OCT. Excluded from this study were patients with myopic eyes of $-4 \mathrm{D}$ or worse, patients who had undergone intraocular surgery (eg, cataract surgery) within the last 6 months, patients who had undergone photodynamic therapy and pegaptanib intravitreal injection within 6 months after their initial ranibizumab vitreous injection, and patients whose follow-up period after their initial ranibizumab intravitreal injection was $<12$ months.

In all subjects, we examined whether VMA was present or absent via the use of a spectral domain OCT system (SPECTRALIS ${ }^{\circledR}$ OCT; Heidelberg Engineering, Heidelberg, Germany) prior to ranibizumab intravitreal injection. The judgment criteria consisted of considering patients in the VMA (+) group as those whose OCT findings clearly indicated that their posterior vitreous membrane adhered to their macular region (ie, vitreomacular traction syndrome [VMTS] type) or those whose OCT findings indicated clear ERM. Ranibizumab was administered to all patients monthly for 3 months, and was then administered as needed (ie, pro re nata) when deterioration was observed. The criteria for retreatment included the residual subretinal fluid and the exacerbation of CNV. Intravitreal injections were performed by one surgeon in all cases.

In each group, we examined the following three items: 1) AMD type, 2) VA change, and 3) the number of ranibizumab administrations over a 1 -year period, and then compared the findings between the two groups. We investigated whether there was a significant difference between these two groups by using Mann-Whitney's $U$-test.
All treatments were performed at Osaka Medical College Hospital. This study was approved by the Ethics Committee of Osaka Medical College, and was performed in accordance with the tenets set forth in the Declaration of Helsinki. Informed written consent was obtained from all subjects prior to the treatment of intravitreal injection of ranibizumab.

\section{Statement of ethics}

This study was approved by the Ethics Committee of Osaka Medical College.

\section{Results}

Among the 12 eyes of the 12 VMA (+) group patients, there were nine eyes with VMTS type, three eyes with ERM type, five eyes with typical AMD, and seven eyes with PCV. Among the 17 eyes of the $16 \mathrm{VMA}(-)$ group patients, there were 14 eyes with typical AMD and three eyes with PCV.

The time course of the logarithm of the minimum angle of resolution (logMAR) VA in the VMA (+) group is shown in Figure 1A. In that group, three cases markedly worsened during the 1-year period. The time course of the $\log$ MAR VA in the VMA (-) group is shown in Figure 1B. In that group, just one case markedly worsened during the 1-year period. However, no significant difference was found between the two groups in the transformation of the mean $\log$ MAR VA change after the first ranibizumab injection (Figure 2). The mean frequency of ranibizumab administration in the VMA (+) group was 5.6 \pm 2.5 times (range: 3-10 times) during the 1-year period, and that in the VMA (-) group was 3.8 \pm 1.1 times (range: $3-6$ times), thus illustrating a significant difference between the two groups (Mann-Whitney's $U$-test: $P<0.05$ ). However, no significant difference was found between either the typical AMD or PCV in both groups. During the follow-up periods there were no cases with spontaneous occurrence of PVD induced by intravitreal injection on the basis of OCT findings.

\section{Discussion}

There have been recent reports on whether VMA is also modifying the pathological condition in AMD, which is an aspect that had previously not received much attention from researchers. ${ }^{4-18}$ We previously reported findings in regard to the vitreous surgery that we performed on 11 exudative AMD cases without PVD. ${ }^{13}$ In that study, by creating artificial PVD, we observed a decrease in activity of CNV in eight eyes. Following the publication of that study, subsequent reports revealed that with respect to AMD, PVD is scarce, and that the posterior vitreous nondetached eye is a risk factor of 


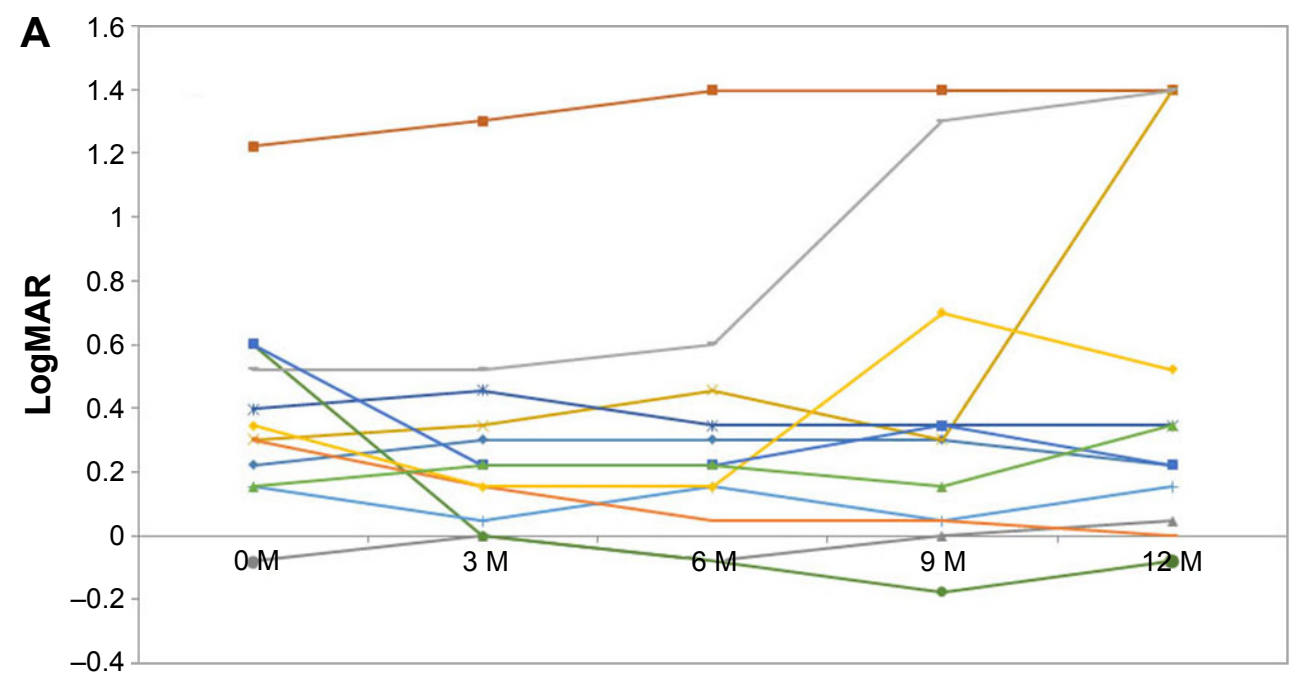

Time course

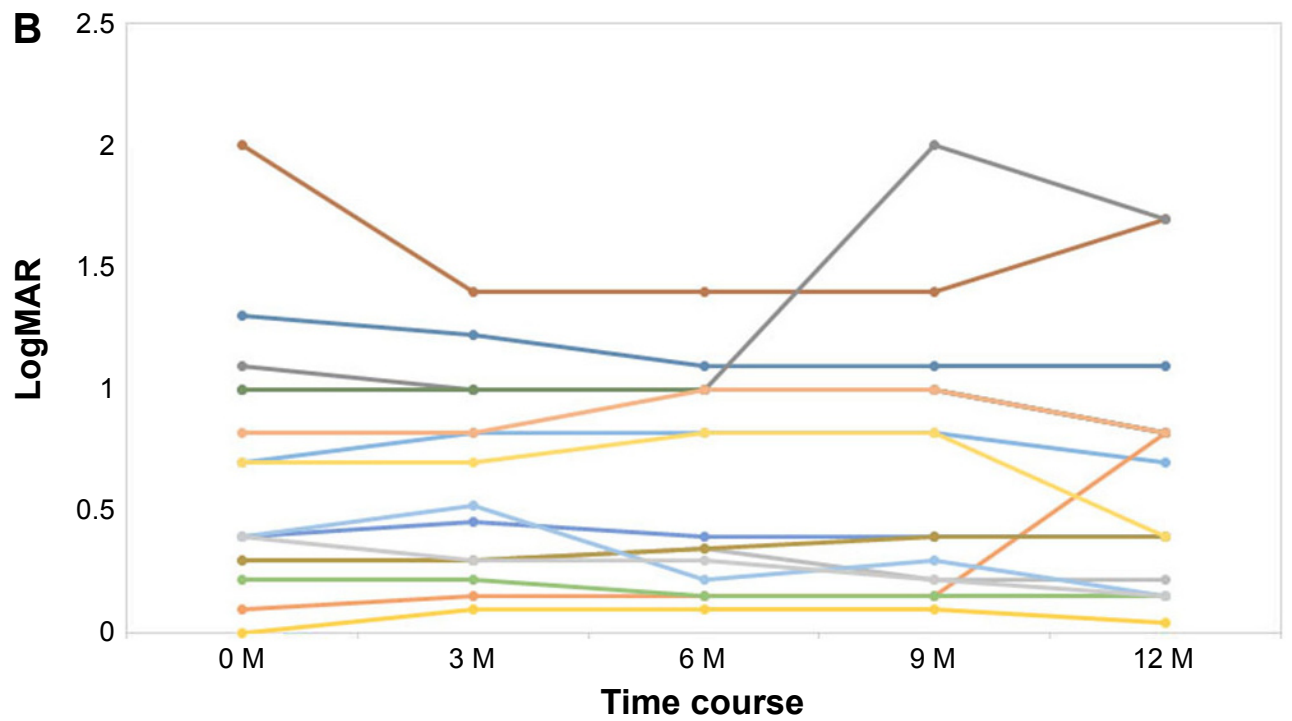

Figure I The time course of logarithm of the minimum angle of resolution (logMAR) visual acuity (VA) for the vitreomacular adhesion (VMA) (+) group (A) and VMA (-) group (B).

Notes: Over the I-year period, three cases markedly worsened in the VMA (+) group, while only one case markedly worsened in the VMA (-) group.

AMD, that vitreous surgery results in fewer onsets of AMD compared with fellow eyes with vitreous hemorrhage, and that $\mathrm{CNV}$ tends to regress post-vitreous surgery for AMD.

Lee et al compared the therapeutic effects of anti-VEGF therapy between 38 eyes with VMA and 110 eyes without VMA. ${ }^{14}$ Their results indicated that there was no difference in the thickness of the foveal retinal membrane in both groups, both of which were reported to have improved. However, improvement of VA was obtained in the VMA (-) group, while no significant improvement of VA was obtained in the VMA (+) group. These results suggest that the effect of anti-VEGF therapy may be difficult to obtain in cases of exudative AMD, in which the posterior vitreous is not detached. Mayr-Sponer et al reported that the configuration of the vitreomacular interface seems to have an important effect on visual outcomes and need for retreatment. ${ }^{18}$ Mojima et al reported that among exudative AMD cases undergoing antiVEGF therapy, there were cases in which VMA was relieved with the progression of PVD during the course of treatment, and cases in which exudative lesions were relieved. ${ }^{9}$ Veloso et al also described similar results. ${ }^{19}$

The findings obtained in this present study revealed that only the number of injections of anti-VEGF therapy was reduced. No significant difference was observed between the two groups in regard to the degree of VA improvement. This finding differed from that reported by Lee et al, and it may be related to differences between races. In a study involving Japanese patients, Nomura et al examined the retinal vitreous 


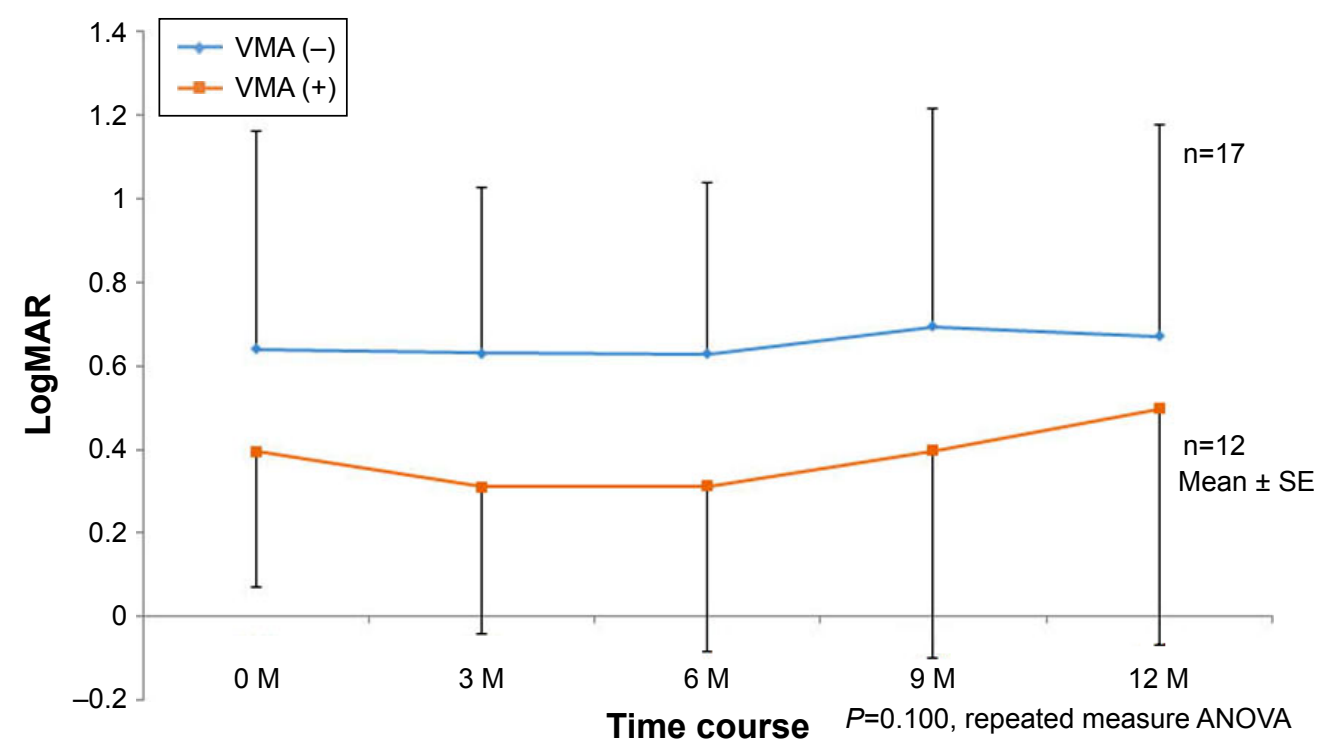

Figure 2 The transformation of the mean logarithm of the minimum angle of resolution (logMAR) visual acuity change after the first ranibizumab injection. Notes: No significant difference was found between the two groups.

Abbreviations: VMA, vitreomacular adhesion; ANOVA, analysis of variance; SE, standard error.

interface in typical AMD cases and PCV, and found that the AMD cases had a higher frequency of VMA and that there was no difference of PCV compared with the control group subjects. ${ }^{20}$ The findings we obtained in this present study showed that there was no particular difference between typical AMD and PCV; the amount of data available in this study is limited because of the small number of cases, and future evaluation is needed.

Various theorizations have been made as to why VMA acts as a deterioration factor in AMD cases. Although it has been theorized that chronic mild inflammation contributes to the deterioration of AMD by VMA, ${ }^{4}$ there is no inflammatory finding in idiopathic macular hole or idiopathic macular epithelium cases that develop with similar traction, so this theory cannot be accepted. ${ }^{23}$ Moreover, it has been theorized that VMA influences VEGF and oxygen concentration. ${ }^{24}$ As vitreous gel consumes oxygen, the presence of VMA is likely to cause hypoxia near the macula, and as a result, the VEGF concentration rises, thus possibly leading to the onset of CNV.

Karaca et al speculated that the presence of ERM in association with AMD may decrease the penetration of the anti-VEGF drugs through these membranes, which may act as a physical barrier. ${ }^{23}$ It is also possible that VMA acts chronically and that mechanical stress acts on constituent cells of the retina and choroid of the macula, thereby changing the expression of cytokines at that site. Suzuma et al reported that in experiments using cultured glial cells, the expression of VEGF in those cells increased by mechanical extension stimulation. ${ }^{24}$ It is also conceivable that the expression of these cytokines may be caused by the changes in the intracellular signal transduction through the stretch-activated channel, which is present in the cell membrane. ${ }^{25}$ In this present study, all cases were treated with ranibizumab; however, the results might have been different if a different anti-VEGF agent had been used.

In conclusion, the results that we obtained in this present study, as well as those obtained in the previous reports, make us believe that VMA may be involved in the progress of the AMD pathology. As we reported in our previous study, it is conceivable that creating artificial PVD with vitreous surgery could be a new treatment, and that vitreous surgery could be considered for treating AMD patients with VMA in whom anti-VEGF therapy is ineffective.

\section{Acknowledgments}

The authors wish to thank John Bush for reviewing the manuscript.

\section{Disclosure}

The authors report no conflicts of interest in this work.

\section{References}

1. Kishi S, Hagimura N, Shimizu K. The role of the premacular liquefied pocket and premacular vitreous cortex in idiopathic macular hole development. Am J Ophthalmol. 1996;122(5):622-628.

2. Kishi S, Shimizu K. Oval defect in detached posterior hyaloid membrane in idiopathic preretinal macular fibrosis. Am J Ophthalmol. 1994; 118(4):451-456. 
3. Lewis H, Abrams GW, Blumenkranz MS, Campo RV. Vitrectomy for diabetic macular traction and edema associated with posterior hyaloidal traction. Ophthalmology. 1992;99(5):753-759.

4. Krebs I, Brannath W, Glittenberg C, Zeiler F, Sebag J. Binder SPosterior vitreomacular adhesion: a potential risk factor for exudative age-related macular degeneration? Am J Ophthalmol. 2007;144(5):741-746.

5. Wheatley HM. Posterior vitreomacular adhesion and exudative agerelated macular degeneration. Am J Ophthalmol. 2008;145(4):765.

6. Schmidt JC, Mennel S, Meyer CH, Kroll P. Posterior vitreomacular adhesion: a potential risk factor for exudative age-related macular degeneration. Am J Ophthalmol. 2008;145(6):1107.

7. Robison CD, Krebs I, Binder S, et al. Vitreomacular adhesion in active and end-stage age-related macular degeneration. Am J Ophthalmol. 2009; 148(1):79-82.

8. Green-Simms AE, Bakri SJ. Vitreomacular traction and age-related macular degeneration. Semin Ophthalmol. 2011;26(3):137-138.

9. Mojana F, Cheng L, Bartsch DU, et al. The role of abnormal vitreomacular adhesion in age-related macular degeneration: spectral optical coherence tomography and surgical results. Am J Ophthalmol. 2008; 146(2):218-227.

10. Lee SJ, Lee CS, Koh HJ. Posterior vitreomacular adhesion and risk of exudative age-related macular degeneration: paired eye study. Am J Ophthalmol. 2009;147(4):621-626.

11. Roller AB, Mahajan VB, Boldt HC, Abramoff MD, Russell SR, Folk JC. Effects of vitrectomy on age-related macular degeneration. Ophthalmology. 2010;117(7):1381-1386.

12. Sakamoto T, Sheu SJ, Arimura N, et al. Vitrectomy for exudative age-related macular degeneration with vitreous hemorrhage. Retina. 2010;30(6):856-864.

13. Ikeda T, Sawa H, Koizumi K, Yasuhara T, Yamasaki T. Pars plana vitrectomy for regression of choroidal neovascularization with age-related macular degeneration. Acta Ophthalmol Scand. 2000;78(4):460-464.

14. Lee SJ, Koh HJ. Effects of vitreomacular adhesion on anti-vascular endothelial growth factor treatment for exudative age-related macular degeneration. Ophthalmology. 2011;118(1):101-110.

15. Houston SK 3rd, Rayess N, Cohen MN, Ho AC, Regillo CD. Influence of vitreomacular interface on anti-vascular endothelial growth factor therapy using treated and extended treatment protocol for age-related macular degeneration. Retina. 2015;35(9):1757-1764.
16. Ciulla TA, Ying GS, Maguire MG, et al; Comparison of Age-Related Macular Degeneration Treatments Trials Research Group. Influence of the vitreomacular interface on treatment outcomes in the comparison of age-related macular degeneration treatments trials. Ophthalmology. 2015;122(6):1203-1211.

17. Waldstein SM, Ritter M, Simader C, Mayr-Sponer U, Kundi M, Schmidt-Erfurth U. Impact of vitreomacular adhesion on ranibizumab mono- and combination therapy for neovascular age-related macular degeneration. Am J Ophthalmol. 2014;158(2):328.e1-336.e1.

18. Mayr-Sponer U, Waldstein SM, Kundi M, et al. Influence of the vitreomacular interface on outcomes of ranibizumab therapy in neovascular age-related macular degeneration. Ophthalmology. 2013;120(12): 2620-2629.

19. Veloso CE, Kanadani TM, Pereira FB, Nehemy MB. Vitreomacular interface after anti-vascular endothelial growth factor injections in neovascular age-related macular degeneration. Ophthalmology. 2015; 122(8):1569-1572.

20. Nomura Y, Ueta T, Iriyama A, et al. Vitreomacular interface in typical exudative age-related macular degeneration and polypoidal choroidal vasculopathy. Ophthalmology. 2011;118(5):853-859.

21. Holekamp NM. The vitreous gel: more than meets the eye. Am J Ophthalmol. 2010;149(1):32-36.

22. Stefánsson E, Geirsdóttir A, Sigurdsson H. Metabolic physiology in age related macular degeneration. Prog Retin Eye Res. 2011;30(1): 72-80.

23. Karaca EE, Kepez Yldz B, Çubuk MÖ, Özdek Ş. Epiretinal membranes in neovascular age-related macular degeneration: effect on outcomes of anti-vascular endothelial growth factor therapy. Retina. 2015;35(8): $1540-1546$.

24. Suzuma I, Suzuma K, Ueki K, et al. Stretch-induced retinal vascular endothelial growth factor expression is mediated by phosphatidylinositol 3-kinase and protein kinase C (PKC)-zeta but not by stretch-induced ERK1/2, Akt, Ras, or classical/novel PKC pathways. J Biol Chem. 2002; 277(2):1047-1057.

25. Groschner K. Two ways to feel the pressure: an endothelial $\mathrm{Ca}(2+)$ entry channel with dual mechanosensitivity. Cardiovasc Res. 2002; 53(1):9-11.
Clinical Ophthalmology

\section{Publish your work in this journal}

Clinical Ophthalmology is an international, peer-reviewed journal covering all subspecialties within ophthalmology. Key topics include: Optometry; Visual science; Pharmacology and drug therapy in eye diseases; Basic Sciences; Primary and Secondary eye care; Patient Safety and Quality of Care Improvements. This journal is indexed on

\section{Dovepress}

PubMed Central and CAS, and is the official journal of The Society of Clinical Ophthalmology (SCO). The manuscript management system is completely online and includes a very quick and fair peer-review system, which is all easy to use. Visit http://www.dovepress.com/ testimonials.php to read real quotes from published authors. 